\title{
Erratum to: A novel technique of ab interno glaucoma surgery: follow-up results after 24 months
}

Bojan Pajic • Grigoris Pallas • Heinrich Gerding •

Matthias Böhnke

Published online: 19 November 2010

(C) Springer-Verlag 2010

Erratum to: Graefes Arch Clin Exp Ophthalmol DOI 10.1007/s00417-005-0041-4

The original version of this article, unfortunately, contained a mistake. The name of the third author should have been Heinrich Gerding instead of Gerding Heinrich.

The online version of the original article can be found at http://dx.doi. org/10.1007/s00417-005-0041-4.

B. Pajic $(\bowtie) \cdot$ G. Pallas $\cdot$ H. Gerding $\cdot$ M. Böhnke

AZP Augenzentrum,

Titlisstrasse 44,

5734 Reinach, Switzerland

e-mail: bpajic@datacomm.ch 